\title{
Increased Excretion of Modified Adenine Nucleosides by Children with Adenosine Deaminase Deficiency
}

\author{
ROCHELLE HIRSCHHORN, ${ }^{(58)}$ HOWARD RATECH, ARYE RUBINSTEIN, \\ PHOTINI PAPAGEORGIOU, HERNANT KESARWALA, ERWIN GELFAND, AND \\ VIVIEN ROEGNER-MANISCALCO

\begin{abstract}
Departments of Medicine and Pathology, New York University School of Medicine, New York, New York /R.H., H.R., and V.R.-M.]; Department of Pediatrics, Albert Einstein College of Medicine, Bronx, New York [A.R.J; Department of Pediatrics, Rutgers University Medical School, Piscataway, New Jersey [P.P., and H.K.J; and Department of Pediatrics, Hospital for Sick Children, Toronto, Ontario, Canada [E.G.]
\end{abstract}

\begin{abstract}
Summary
We have identified seven adenine nucleosides in urines of untreated adenosine deaminase (ADA) deficient patients, four of which (adenosine, $\mathbf{2}^{\prime}$-deoxyadenosine, 1 -methyladenosine and $\mathbf{N}^{6}$ methyladenosine) have been previously identified in urines of normals and/or ADA deficient patients. We confirm that ADA deficient patients excrete markedly increased amounts of $2^{\prime}$-deoxyadenosine $(582 \pm 363$ versus normal of $<0.1$ nmoles $/ \mathrm{mg}$ creatinine) and increased amounts of adenosine $(29.4 \pm 5.7$ versus normal of $4.12 \pm 1.0$ nmoles $/ \mathrm{mg}$ creatinine).

We have found three other modified adenine nucleosides previously undetected in human urine. These three compounds are $2^{\prime}$ O-methyladenosine, $\mathrm{N}^{6}, \mathbf{2}^{2}$-O-dimethyladenosine and an as yet incompletely characterized modified adenine nucleoside, $\mathbf{R}$-adenosine. Only ADA deficient patients excrete detectable amounts of 2 '-O-methyladenosine $(2.1 \pm 1.1$ versus normal of $<0.1$ nmoles/ mg creatinine), whereas both normals and ADA deficient children excrete $\mathbf{N}^{6}, \mathbf{2}^{2}$-O-dimethyladenosine and $\mathbf{R}$-adenosine. However, ADA deficient patients do excrete increased amounts of $R$-adenosine (5.5 \pm 1.0 versus normal of $1.4 \pm 0.4 \mathrm{nmoles} / \mathrm{mg}$ creatinine).
\end{abstract}

\section{Speculation}

Accumulation in ADA deficient patients of two newly detected modified adenine nucleosides (2'-O-methyladenosine and $\mathbf{R}$-adenosine) or their metabolites could play a role in explaining the profound abnormalities of $B$ cell function seen in ADA deficiency but not in purine nucleoside phosphorylase deficiency. This differential involvement of $B$ cell function is not easily explained by accumulation of deoxytrinucleotides, which occurs in both disorders.

Inherited deficiency of the purine salvage enzyme, adenosine deaminase (ADA) results in a fatal infantile syndrome of severe combined immunodeficiency (ADA-SCID) $(10,15,22,25,30)$. Children with ADA deficiency have a profound defect in both cellular and humoral immunity, although in 10-15\% of cases, the humoral defect may initially be less severe (22). Affected children accumulate and/or excrete markedly increasd amounts of the ADA substrates, adenosine and 2 '-deoxyadenosine, and the phosphorylated metabolite, deoxy ATP (dATP) $(3,5,6,9,26-28,32$, $37,41,46,50$ ).

Several pathophysiologic mechanisms have been proposed whereby accumulation of ADA substrates and their metabolites would result in immunodeficiency $(5,12,15,16,21,24,40,52)$. The largest body of evidence supports the hypothesis that dATP, an inhibitor of ribonucleotide reductase, accumulates preferen- tially in, and prevents proliferation of, immunocompetent cells, primarily of the $T$ cell class $(2,5,6,23,38,49,54)$. There is also in vivo and/or in vitro evidence for alternative mechanisms of toxicity, which would operate via depletion of pyrimidine pools, depletion of phosphoribosyl pyrophosphate and increases in cyclic AMP or S-adenosyl homocysteine $(16,21,24,40,46,55)$. All of these mechanisms are dependent on accumulation of the substrates of ADA, adenosine and 2'-deoxyadenosine.

In addition to adenosine and 2'-deoxyadenosine, several other modified adenine nucleosides occur naturally $(17,19)$ and are substrates for ADA $(1,18,43,56)$. Such naturally occurring modified adenine nucleosides might be expected to also accumulate in ADA deficient patients and possibly contribute to toxicity. We have, therefore, sought to determine if these modified adenine nucleosides are uniquely present, or present in increased amounts, in urine of ADA deficient patients. We have identified seven compounds in urines of ADA deficients, four of which (adenosine, $2 '$-deoxyadenosine, 1-methyladenosine and $\mathrm{N}^{6}$-methyladenosine) have been previously identified in urines of normals and/or ADA deficient patients $(4,9,27,28,32,36,37,50)$. We have additionally found three other substrates of ADA not previously detected in urine. These three compounds newly identified in urine are $2^{\prime}-\mathrm{O}$ methyladenosine, $\mathrm{N}^{6}, 2^{\prime}$-O-dimethyladenosine and an as yet incompletely characterized modified adenine nucleoside, $\mathrm{R}$-adenosine. Only ADA deficient patients excrete detectable amounts of 2'-O-methyladenosine, whereas both normal and ADA deficient children excrete $\mathrm{N}^{6}, 2^{\prime}$-O-dimethyladenosine and the as yet unidentified ADA substrate R-adenosine. However, ADA deficient patients excrete increased amounts of $\mathbf{R}$-adenosine.

\section{MATERIALS AND METHODS}

Materials. Nucleosides were obtained from Sigma Co. (St. Louis, MO) or P\&L (Milwaukee, WI). 2'-O-Methylinosine was generated by incubation of $2^{\prime}-\mathrm{O}$-methyladenosine with calf intestinal ADA, type 1 from Sigma, and purified by high pressure liquid chromatography. 5'-Methylthioadenosine was generated by acid hydrolysis of $S$-adenosyl methionine (45). $5^{\prime}$-deoxyadenosine and $\mathrm{N}^{6}$-threoninocarbonyl adenosine were the generous gifts of respectively Dr. G. Elion and Dr. G.B. Chheda.

Anion exchange chromatography. Urines (stored frozen at $-70^{\circ} \mathrm{C}$ with $0.01 \%$ sodium azide) were chromatographed on an anion exchange column (Biorad AG 1-X2, Richmond, CA) essentially as described by Kuttesch, et al. (32) except that four fractions were collected. Fraction 1, 1-6 ml; fraction 2, 7-31 ml; fraction 3, $32-52 \mathrm{ml}$ and fraction $4,53-73 \mathrm{ml}$ (eluting after the addition of acid). Adenosine and 2'-deoxyadenosine eluted in fraction 2 and adenine in fraction 4 , as previously described $(32,36)$. The elution 
profiles of several authentic compounds, including modified adenine and guanine nucleosides and bases are shown in Figure 1.

High pressure liquid chromatography (HPLC). Urines (fractionated and unfractionated) were analyzed by HPLC on C18 $\mu$ Bondapak columns (Waters Co., Milford, MA) by methods previously described (42) except that the gradient went from 0 to $40 \%$ methanol in $60 \mathrm{~min}$. For further identification, peaks of interest were collected, dried under nitrogen, reconstituted with water, and reanalyzed following either treatment with $A D A$, acid hydrolysis or chromatography on Affigel 601 (Biorad, Richmond, CA). UV ratios of compounds were determined by simultaneous monitoring at the two wavelengths specified. Retention times of relevant nucleosides and bases are listed in Table 1.
Peak shift and acid hydrolysis. Samples and authentic compounds were incubated with and without calf intestinal ADA (Sigma Type 1, St. Løuis, MO) $(20,42)$ at $0.08,1.5$ and $15 \mathrm{IU} / \mathrm{ml}$ final concentration for $1-2 \mathrm{~h}$ at $37^{\circ} \mathrm{C}$ and then analyzed by HPLC (Fig. 2 and Table 1). For hydrolysis of nucleosides to bases, peaks of interest were collected by HPLC, concentrated, reconstituted with $\mathrm{H}_{2} \mathrm{O}$ and an aliquot boiled for $30 \mathrm{~min}$ in $0.45 \mathrm{~N}$ perchloric acid and neutralized with $\mathrm{KOH}$. The authentic compounds adenosine, 2'-deoxyadenosine, 2'-O-methyladenosine, $\mathbf{N}^{6}$-methyladenosine, 1-methyladenosine, $\mathbf{N}^{6}, \mathbf{N}^{6}$,-dimethyladenosine and $\mathbf{N}^{6}$ isopentenyladenosine were hydrolyzed under the same conditions and the reaction products analyzed by HPLC. $\mathrm{N}^{2}$-methylguanosine eluted in the last of the anion exchange fractions (Fig. 1) and

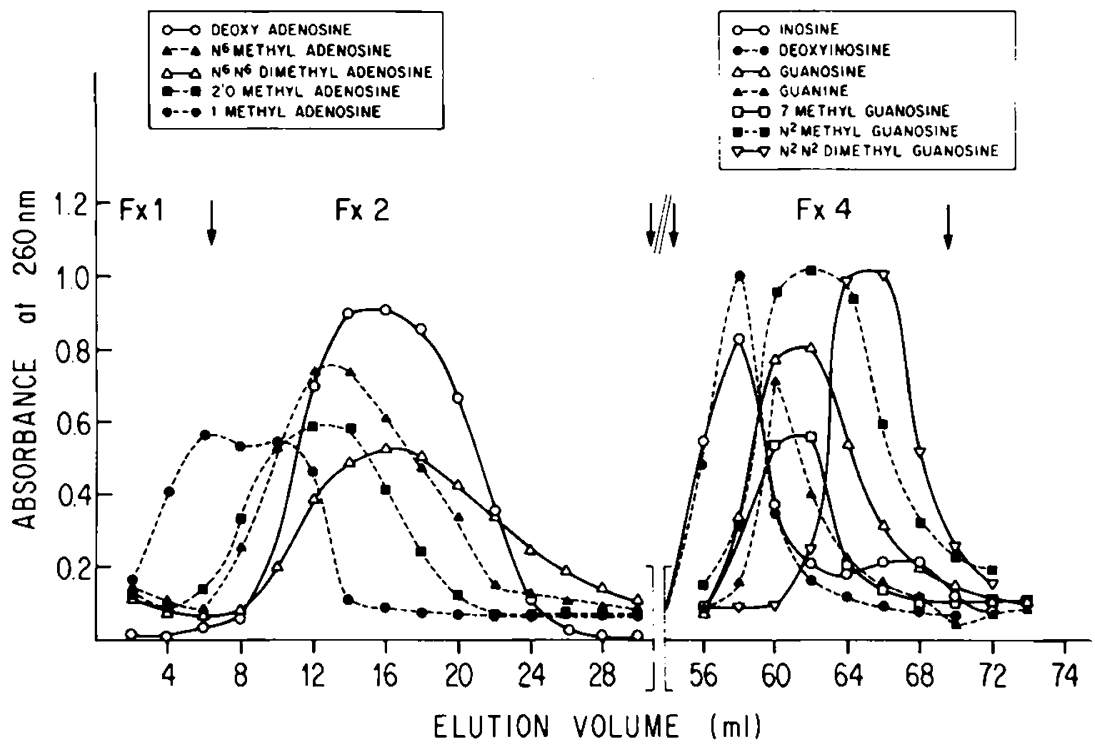

Fig. 1. Elution of methylated nucleosides from dowex AG 1 X2. Authentic compounds were diluted and chromatographed on Dowex AG 1 X2 columns as described in "Materials and Methods". All the modified adenine nucleosides tested (as well as adenosine) eluted in the second fraction except for 1-methyladenosine which eluted in the first and second fractions. Isopentenyl adenosine could not be recovered by this method (not shown).

Table 1. Relative retention times of modified adenine nucleosides and the products generated by deamination or acid hydrolysis

\begin{tabular}{|c|c|c|c|c|c|}
\hline Compound & $\begin{array}{l}\frac{\text { Retention time }}{\text { Retention time }} \\
\text { Adenosine }\end{array}$ & $\begin{array}{l}\text { Deamination } \\
\text { product }\end{array}$ & $\begin{array}{c}\frac{\text { Retention time }^{2}}{\text { Retention time }} \\
\text { Inosine }\end{array}$ & Hydrolysis product & $\begin{array}{c}\frac{\text { Retention time }}{2} \\
\begin{array}{c}\text { Retention time } \\
\text { Adenin }\end{array}\end{array}$ \\
\hline 1-Methyladenosine' & 0.45 & 1-methylinosine & 1.36 & 1-methyladenine & 0.39 \\
\hline $2^{\prime}$-Deoxyadenosine' & 1.11 & $2^{\prime}$-deoxyinosine & 1.19 & adenine & 1.00 \\
\hline $\begin{array}{l}\mathrm{N}^{6}, \text { threoninocarbonyladeno- } \\
\text { sine }\end{array}$ & 1.23 & $\mathrm{NT}^{4}$ & & NT & \\
\hline 2'-O-Methyladenosine' & 1.32 & 2'-O-methylinosine & 1.41 & adenine & 1.00 \\
\hline $\mathbf{N}^{6}$-Methyladenosine ${ }^{1}$ & 1.49 & inosine & 1.00 & $\mathrm{~N}^{6}$-methyladenine & 1.78 \\
\hline 3'-O-Methyladenosine & 1.49 & 3'-O-methylinosine & 1.64 & adenine & 1.00 \\
\hline $\mathbf{N}^{6}, 2^{\prime}$-O-Dimethyladenosine ${ }^{1}$ & 1.89 & 2'-O-methylinosine & 1.41 & adenine & 1.00 \\
\hline$N^{6}, N^{6},-$ Dimethyladenosine & 2.21 & inosine & 1.00 & $\mathbf{N}^{6}, \mathbf{N}^{6}$,-dimethyladenine & 3.00 \\
\hline Isopentenyladenosine & 3.36 & inosine & 1.00 & "isopentenyladenine"3 & 3.34 \\
\hline
\end{tabular}

' Compounds isolated from urine as well as authentic compounds, treated with ADA and also acid hydrolyzed. Retention times of urinary compounds were identical to those of the authentic compounds, as determined by coelution.

${ }^{2}$ Inosine and adenine have retention time relative to adenosine (1.00) of 0.58 and 0.70 . All closely eluting compounds (e.g., $5^{\prime}$-deoxyadenosine, $\mathrm{N}^{6}$ threoninocarbonyladenosine, 2'-O-methyladenosine and $\mathrm{R}$-adenosine) were injected in mixtures to confirm that they migrated separately from each other and their order of elution. Additional compounds not listed but excluded as R-adenosine on the basis of different retention tiemes include 3'deoxyadenosine and 5'-deoxy, 5'-methylthioadenosine. 3'-deoxyinosine was also excluded as $R$-inosine.

${ }^{3}$ The hydrolysis product of isopentenyladenosine is referred to as "isopentenyl adenine" for brevity. The hydrolysis reaction reportedly gives rise to several compounds by a less direct route. Authentic isopentenyl adenine coelutes with isopentenyladenosine in this system.

${ }^{4} \mathrm{NT}=$ not tested. 

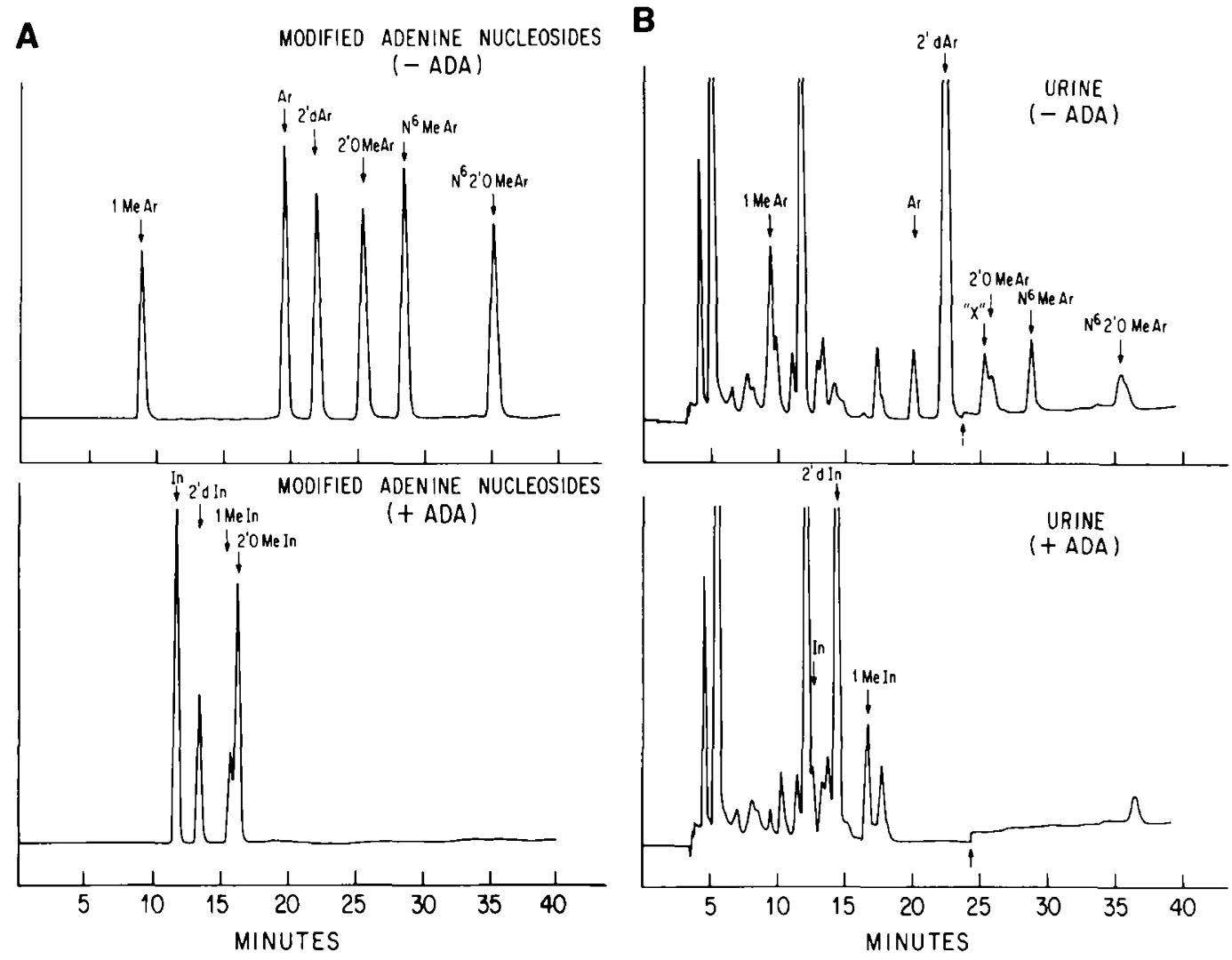

Fig. 2A. Reverse phase HPLC (C18 $\mu$ BONDAPAK) of modified adenine nucleosides. Elution of authentic adenine nucleosides ( upper panel) and their deamination products (lower panel) monitored at $260 \mathrm{~nm}$. The elution times of additional modified nucleosides not detected in urine are indicated in Table 1. The authentic compounds were individually incubated with varying concentrations of adenosine deaminase and rechromatographed to determine elution times of the respective deamination products (Table 1). The tracing (lower panel) demonstrates the results of treatment with adenosine deaminase of a mixture of the nucleosides present in the upper panel.

Fig. 2B. HPLC of urine of an ADA deficient child before and after incubation with exogenous adenosine deaminase. The second anion exchange column fraction (see "Materials and Methods" and Fig. 1) from urine of an untreated ADA deficient child was concentrated and analyzed by HPLC, monitoring at $260 \mathrm{~nm}$. The arrow indicates a 4-fold increase in sensitivity to a full scale of 0.02 . Peaks coeluting with 1-methyladenosine (I Me Ar), adenosine (Ar), 2-deoxyadenosine ( 2 ' dAr), an unidentified modified adenine nucleoside ( $\mathrm{R}$-adenosine or " $\mathrm{X}$ "), 2'-O-methyladenosine (2'-O Me Ar), $\mathrm{N}^{6}$-methyladenosine $\left(\mathrm{N}^{6} \mathrm{Me} \mathrm{Ar}\right)$ and $\mathrm{N}^{6}, 2^{\prime}$-O-dimethyladenosine $\left(\mathrm{N}^{6} 2^{\prime} \mathrm{O} \mathrm{Me} \mathrm{Ar}\right.$ ) (indicated in the upper panel) all disappeared after incubation with adenosine deaminase (lower panel). Peaks appeared after ADA treatment (lower panel) with the retention times of inosine (derived from deamination of adenosine and $\mathrm{N}^{6}$-methyladenosine), $2^{\prime}$-deoxyinosine (from $2^{\prime}$-deoxyadenosine) and 1-methylinosine (from 1-methyladenosine). (The presumed and authentic 1-methyladenosine, $\mathrm{N}^{6}, 2^{\prime}$-O-dimethyladenosine and $\mathrm{N}^{6}$-methyladenosine peaks required approximately 200 - and 20 -fold higher concentrations of ADA than those used to completely deaminate adenosine or 2'-deoxyadenosine.) 2'-O-methylinosine (2'-O Me In) (from 2'-O-methyladenosine and $\mathrm{N}^{6}, 2^{\prime}$-O-dimethyladenosine) and $\mathrm{X}$-inosine elute shortly after l-methylinosine (see Table 1) and are "buried" in this chromatogram primarily because of the presence of an unidentified interfering peak eluting shortly after 1-methylinosine, the high concentrations of 1 -methylinosine relative to $2^{\prime}$-Omethylinosine and R-inosine as well as the decreased sensitivity of detection of "inosine" as compared with "adenosine" compounds at $260 \mathrm{~nm}$, the wavelength at which this chromatogram was monitored.

The chromatogram is only illustrative and the indicated identifications were based on studies where peaks were collected individually, concentrated and rechromatographed with and without incubation with ADA to determine coelution and authentic compounds, UV ratios and the retention times listed in Table 1. For studies of 2'-O-methyladenosine and R-adenosine (peak "X"), the two compounds were also separated on Affigel 601 (see text).

it was identified in the HPLC chromatogram both by coelution with the authentic compound and by "peak shift" using exogenous purine nucleoside phosphorylase in the phosphorolytic direction.

Affigel 601 columns. Affigel 601 (Biorad, Richmond, CA), a boronate gel that selectively binds cis-diol compounds at high $\mathrm{pH}$, was swollen and packed as directed and eluted as described for separation of deoxy ribonucleotides and ribonucleotides (54), collecting $1 \mathrm{ml}$ fractions. 2'-Deoxyadenosine and 2'-O-methyladenosine eluted in the first $10 \mathrm{ml}$ with a peak at fractions $3-8$; adenosine and $\mathrm{N}^{6}$-methyladenosine bound and were eluted only after the change to lower $\mathrm{pH}$ with a peak in fractions 19-24.

Uric acid was determined using uricase (Sigma, Type 1), creatinine with Sigma Kit 555 and protein by the method of Lowry, et al. (33).

Patients. Patients 1 and 2 are sibs whose case histories have been previously reported (44). Patient 1 was diagnosed prenatally as ADA deficient. The diagnosis was confirmed both enzymati- cally and by in vitro tests of immune function. He was clinically healthy at the start of the study. The case history for patient 3 has also been reported (26). She was critically ill for the first 4 months of the study. Patient 4 was a 6-month-old child severely ill with multiple infections and classic manifestations of SCID (14). Three of the control patients studied were similar to the ADA deficients in that they were either clinically critically ill or immunodeficient (controls 1-3). The ages of controls (6 months to 3 years) essentially overlapped with those of the ADA deficients at the onset of study (6 wk to $2 \frac{1 / 2}{2}$ years).

\section{RESULTS}

Analysis of fractionated urine by HPLC and detection of urinary $A D A$ substrates. We fractionated urines from ADA deficient and nonADA deficient, immunodeficient and normal children on anion exchange columns, collected and lyophilised the fraction 
which contains adenine nucleosides (fraction 2, see "Materials and Methods") and analyzed this fraction by HPLC. We found seven compounds in urines of ADA deficient children that absorbed UV at $260 \mathrm{~nm}$ and behaved as if they were substrates for ADA. Thus, all seven peaks disappeared from the chromatogram after incubation with exogenous ADA (Figure $2 B$ ).

Identification and quantitation of four $A D A$ substrates known to be present in urine. Four of the seven peaks coeluted respectively with 1-methyladenosine, adenosine, $2^{\prime}$-deoxyadenosine or $\mathrm{N}^{6}$ methyladenosine and had the same $250 / 260$ and 280/260 UV ratios as the authentic compounds. When each of the peaks was collected individually, an aliquot incubated with ADA and rechromatographed, each of the original peaks disappeared and a new peak appeared that coeluted with and had the same 250/260 and $280 / 260 \mathrm{UV}$ ratios as the expected authentic product of deamination and which represented over $90 \%$ recovery from the original peak (Table 1 and Fig. 2). The first three compounds identified, 1-methyladenosine, adenosine and $\mathbf{N}^{6}$-methyladenosine, have been previously detected in urine of normals (4) whereas 2 -deoxyadenosine has been found previously only in urine of ADA deficient children $(9,26,27,32,36,50)$.

The four ADA deficient children excreted dramatically increased amounts of 2'-deoxyadenosine, ranging from 220-1090 nmoles/mg creatinine (Table 2 ), similar to previously reported values. NonADA deficient children, whether immunodeficient or healthy, excreted undetectable $(<0.01$ nmoles $/ \mathrm{mg}$ creatinine) amounts of 2 -deoxyadenosine. Excretion of adenosine was also increased, although less markedly, with an average excretion of $29.4 \pm 5.7$ compared to excretion of $4.1 \pm 1.0$ nmoles $/ \mathrm{mg}$ creatinine by the nonADA deficient children. Quantitation of 1-methyladenosine or $\mathrm{N}^{6}$-methyladenosine excretion was complicated by the fact that the two compounds can interconvert in solution (19). Combined 1-methyladenosine $+\mathrm{N}^{6}$-methyladenosine excretion by the ADA deficient children was only slightly increased (approximately 2 -fold) when compared with excretion by the three younger children ( $102 \pm 24$ versus $49 \pm 3.6 \mathrm{nmoles} / \mathrm{mg}$ creatinine). 1-Methyladenosine excretion by both ADA deficient and nonADA deficient young children was markedly greater than $\mathrm{N}^{6}$ methyladenosine excretion. The two older, healthy children ex- creted markedly lower concentrations of $\mathbf{N}^{6}+1$-methyladenosine, primarily because of markedly decreased excretion of 1-methyladenosine (Table 2). [An additional healthy 6-month-old infant also excreted 4-fold higher amounts of 1 -methyladenosine ( 40 nmoles/ mg creatinine) than did the healthy 3 -year-old children, suggesting that I-methyladenosine excretion decreases with age.]

Three additional urinary $A D A$ substrates. We found three additional compounds that behaved as if they were substrates for ADA and have not been previously described in urines of normals or of ADA deficient patients. The first two of these three compounds appeared in urine of ADA deficient patients as a double peak eluting shortly after 2 -deoxyadenosine (Figure $2 B$ ). The later eluting component of the double peak eluted with authentic 2 '-Omethyladenosine and was degraded by ADA at concentrations similar to those required to degrade adenosine and authentic $2^{\prime}$ $\mathrm{O}$-methyladenosine. The earlier eluting component of the double peak required higher concentrations of ADA, similar to those required for conversion of $\mathrm{N}^{6}$-methyladenosine to inosine. When this double peak was collected, lyophilised and applied to an Affigel 601 boronate gel column, the presumed 2'-O-methyladenosine eluted in the void volume of the column, consistent with 2 -O-methylation of the ribose moiety and loss of cis-diol groups. The other component bound to Affigel 601 columns and was eluted by lowering the $\mathrm{pH}$. We were, therefore, able to completely separate the two compounds by chromatography on Affigel 601 for further characterization.

Further characterization and quantitation of 2'-O-methyladenosine in urine of $A D A$ deficient children. In addition to having identical retention times (as determined by coelution) and lacking vicinal hydroxyl groups, the presumed $2^{\prime}$-O-methyl compound shared other properties with authentic $2^{\prime}$-O-methyladenosine. The presumed $2^{\prime}$-O-methyladenosine and the compounds generated by deamination ( 2 '-O-methylinosine) and acid hydrolysis (adenine) coeluted with and had UV spectral ratios like those of authentic $2^{\prime}$-O-methyladenosine and the compounds generated by deamination and acid hydrolysis of authentic 2'-O-methyladenosine (Tables 1 and 3 ).

We could not detect any 2'-O-methyladenosine in urines of normal or nonADA deficient, immunodeficient children. We

Table 2. Excretion of adenine nucleosides by $A D A$ deficient and nonADA deficient children (adenosine, $2^{\prime}$-deoxyadenosine, 1 -methyl + $N^{6}$-methyladenosine, $2^{\prime}$-O-methyladenosine and $R$-adenosine)

\begin{tabular}{|c|c|c|c|c|c|c|}
\hline \multirow[b]{2}{*}{ Subjects } & \multirow[b]{2}{*}{ Age } & \multicolumn{5}{|c|}{ Compounds ${ }^{1}$} \\
\hline & & $\mathrm{dAr}$ & $\mathrm{Ar}$ & $\underset{\mathrm{Ar}}{1 \mathrm{Me} \mathrm{Ar}+\mathrm{N}^{6} \mathrm{Me}}$ & 2'O Me Ar & $\mathbf{R} \mathrm{Ar}$ \\
\hline \multicolumn{7}{|l|}{ ADA deficient } \\
\hline 1 & $6 \mathrm{wk}$ & 221 & 37.1 & 111 & 2.1 & 5.2 \\
\hline 2 & $2.5 \mathrm{yr}$ & $414^{3}$ & $23.5^{3}$ & $66^{3}$ & $3.5^{3}$ & $5.3^{3}$ \\
\hline 3 & $6 \mathrm{mo}$ & 1090 & 27.3 & 110 & 2.2 & 6.9 \\
\hline 4 & $6 \mathrm{mo}$ & 572 & 29.8 & 119 & 0.7 & 4.6 \\
\hline $\begin{array}{l}\text { Average } \pm \text { S.D. } \\
\text { NonADA deficien }\end{array}$ & & $582 \pm 363$ & $29.4 \pm 5.7$ & $102 \pm 24$ & $2.1 \pm 1.1$ & $5.5 \pm 1.0$ \\
\hline 1 & $6 \mathrm{mo}$ & $<0.1$ & 4.98 & 46 & $<0.1$ & 2.0 \\
\hline 2 & $6 \mathrm{mo}$ & $<0.1$ & 4.83 & 48 & $<0.1$ & 1.4 \\
\hline 3 & $16 \mathrm{mo}$ & $<0.1$ & 4.76 & 53 & $<0.1$ & 1.4 \\
\hline 4 & $3 \mathrm{yr}$ & $<0.1$ & 5.46 & 10 & $<0.1$ & 1.1 \\
\hline 5 & $3 \mathrm{yr}$ & $<0.1$ & 0.55 & 13 & $<0.1$ & 1.1 \\
\hline Average \pm S.D. & & $<0.1$ & $4.12 \pm 1.00$ & $34 \pm 21$ & $<0.1$ & $1.4 \pm 0.4$ \\
\hline
\end{tabular}

${ }^{1}$ nmoles/mg creatinine: Ar, adenosine; dAr, 2'-deoxyadenosine; $1 \mathrm{Me} \mathrm{Ar}+\mathrm{N}^{6} \mathrm{Me}$ Ar, 1-methyladenosine + ${ }^{6}$-methyladenosine; 2'O Me Ar, 2'methyladenosine and R-Ar, R-adenosine or "Peak X". Compounds were quantitated by determining area as measured by height and width at half peak height, compared with areas of authentic compounds. For R-adenosine and $\mathrm{R}$-inosine, the area/pmole obtained for adenosine and inosine was used. Quantitation of 2'O Me Ar and R-Ar was performed by using several $\mathrm{C}_{18} \mu$ Bondapak Columns, which either optimally separated the substrates (2'-Omethyladenosine and R-adenosine) or the deamination products ( 2 'O-methylinosine and $\mathrm{R}$-inosine) or both on the same column. Values obtained by the two separate methods of quantitation agreed within $10 \%$. We could not ascertain why the commercially packed columns differed in resolution. We made only limited attempts to modify the conditions and were unsuccessful in obtaining resolution on all columns.

${ }^{2}$ Controls: Patients 1 and 2 were immunodeficient, nonADA deficient infants. Patient 2 was severely ill. Patient 3 was a critically ill, nonimmunodeficient child. Patients 4 and 5 were healthy, normal children.

${ }^{3}$ Seventy days following last transfusion. 
Table 3. UV ratios of $2^{\prime}$-O-methyladenosine, $R$-adenosine and the compounds produced by acid hydrolysis or deamination

\begin{tabular}{lcl}
\hline & \multicolumn{2}{c}{ UV ratios } \\
\cline { 2 - 3 } \multicolumn{1}{c}{ Compounds' } & \multicolumn{1}{c}{$250 / 260 \pm$} & $280 / 260 \pm$ \\
& S.D. & S.D. \\
\hline Adenine nucleosides & & \\
Ar authentic & $0.84 \pm 0.03$ & $0.18 \pm 0.01$ \\
2'O MeAr authentic & $0.84 \pm 0.03$ & $0.21 \pm 0.02$ \\
2'O MeAr urinary & $0.87 \pm 0.05$ & 0.22 \\
R-Ar urinary & $0.82 \pm 0.08$ & 0.12 \\
Bases (products of acid hydrolysis) & & \\
Ade authentic & $0.86 \pm 0.01$ & $0.14 \pm 0.02$ \\
Ade from authentic 2'O MeAR & $0.86 \pm 0.01$ & $0.15 \pm 0.01$ \\
Ade from urinary 2'O MeAr & $0.85 \pm 0.06$ & 0.15 \\
R-Ade from urinary R-Ar & $0.84 \pm 0.08$ & $0.17 ; 0.19$ \\
Inosine nucleosides (products of deamina- & & \\
$\quad$ tion) & & \\
In authentic & $1.61 \pm 0.04$ & $0.25 \pm 0.04$ \\
2'O MeIn from authentic 2'O MeAr & $1.54 \pm 0.04$ & $0.26 \pm 0.01$ \\
2'O MeIn from urinary 2'O MeAr & $1.72 \pm 0.23$ & 0.24 \\
R-In from urinary R-Ar & $1.36 \pm 0.20$ & $0.28 \pm 0.04$ \\
\hline
\end{tabular}

' Ar, adenosine; 2'O MeAr, 2'-O-methyladenosine; Ade, adenine; In, inosine.

quantitated 2'-O-methyladenosine in urines of $\mathrm{ADA}$ deficient patients both by measuring the $2^{\prime}$-O-methyladenosine peak and by isolating the peak and measuring the deamination product. Both measurements were in good agreement. 2'-O-Methyladenosine excretion ranged between $0.7-2.2$ nmoles/mg creatinine in three untreated ADA deficient patients (Table 2). A fourth ADA deficient child excreted 3.5 nmoles/mg creatinine 70 days after a prior erythrocyte transfusion. Urine from three infants with various other immunodeficiency disorders and from two normal children were also analyzed. We could not detect 2 '-O-methyladenosine excretion by any of these children with a lower limit of sensitivity ranging from $<0.05$ to $<0.10 \mathrm{nmoles} / \mathrm{mg}$ creatinine.

Further characterization and quantitation of compound $R$-adenosine. We have not as yet identified the first of the two closely eluting ADA sensitive compounds (Fig. 2 and 3). This compound, which we have designated $R$-adenosine or peak " $X$ ", in contrast to 2'-O-methyladenosine, was found in urine of normals as well as in urine of ADA deficient patients. R-adenosine had 250/260 and $280 / 260$ UV spectral ratios of 0.82 and 0.12 , consistent with an adenine nucleoside, but did not comigrate with any of the 16 previously described, modified nucleosides which were tested (Table 1).

The deamination product of $\mathbf{R}$-adenosine eluted slightly after authentic 2'-O-methylinosine and separately from inosine as well as from 1-methyl, 2'-deoxy, 3'-O-methyl or 5'-deoxyinosine (Table 1). The R-inosine had $250 / 260$ and $280 / 260$ UVC ratios consistent with an inosine nucleoside (1.36 and 0.28 ). Treatment of the $R$ inosine with purine nucleoside phosphorylase gave rise to a compound with the retention time of hypoxathine.

We could find no evidence for modification in the $2^{\prime}, 3^{\prime}$ hydroxyl portion of the ribose moiety or modification in the purine ring. Thus, R-adenosine, in contrast to $2^{\prime}$-O-methyladenosine, bound to Affigel 601 columns and eluted with a peak in fractions 23-30, slightly after the adenosine and $\mathrm{N}^{6}$-methyladenosine peaks in fraction 19-24. The $R$-adenosine was very acid labile, being completely hydrolyzed under conditions where only $18 \%$ of adenosine was hydrolyzed $\left(0.1 \mathrm{~N} \mathrm{PCA}\right.$ for $10 \mathrm{~min}$ at $\left.100^{\circ} \mathrm{C}\right)$ and only a single product could be detected under all conditions of hydrolysis. The product of acid hydrolysis coeluted with adenine and had appropriate 250/260 and 280/260 UV ratios (Table 3 and Fig. 3). The coelution of the acid hydrolysis product with adenine indicates that the purine ring is not 1 -methyl, 2-methyl, $\mathrm{N}^{6}$-methyl, $\mathrm{N}^{6}, \mathrm{~N}^{6}$-dimethyl or isopentenyl adenine, all of which had retention times different from adenine (Table 1). The compound, isolated both from normal and ADA deficient urine, was a relatively poor substrate for ADA, requiring concentrations of ADA similar to those needed to deaminate $\mathrm{N}^{6}$-methyladenosine.

We quantitated excretion of $\mathrm{R}$-adenosine both by measuring the area of the peak, using columns which best separated the nucleoside from 2'-O-methyladenosine, and by measuring the area of the deamination product, using columns which best separated the deamination product from 2'-O-methylinosine. The two methods were in good agreement, assuming relative extinction coefficients as for adenosine and inosine. The four ADA deficient children excreted between 4.6 and 6.9 nmoles $R$-adenosine/mg creatinine, compared to normal excretion of $1.4 \pm 0.4$ (Table 2).

$N^{6}, 2^{\prime}-O$-Methyladenosine. The third, previously undescribed ADA sensitive urinary compound coeluted with $\mathrm{N}^{6}, 2^{\prime}$-O-dimethyladenosine. When this peak (isolated from both normal and ADA deficient urine) was incubated with ADA, a peak was generated that coeluted with and had the same $250 / 260$ UV ratios as $2^{\prime}$-O-methylinosine, the deamination product of $\mathrm{N}^{6}, 2^{\prime}$-O-dimethyladenosine. This compound was identified in urine of both normals and ADA deficient patients. The presumed $\mathrm{N}^{6}, 2^{\prime}-\mathrm{O}$ dimethyladenosine peak comigrated with at least one other nonADA sensitive compound and the peak has not as yet been

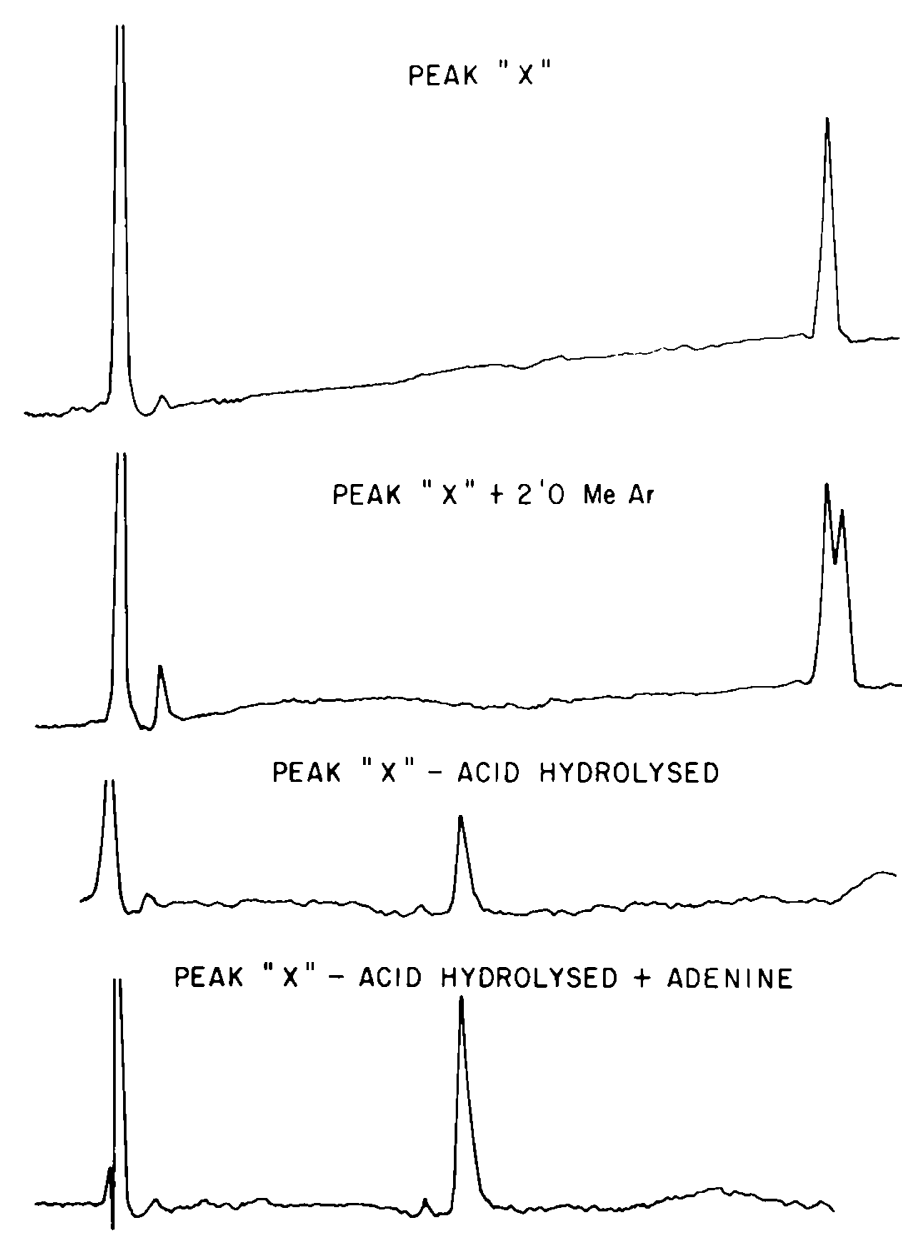

\section{MINUTES}

Fig. 3. Characterization of $\mathrm{R}$-adenosine (peak $\mathrm{X}$ ). The unknown modified adenine nucleoside (peak " $X$ ") (Fig. 2) was collected by HPLC from urine of an ADA deficient child, bound to and eluted from a boronate column (Affigel 601), concentrated and rechromatographed alone (1) and together with authentic 2'-O-methyladenosine (2). The " $X$ " compound was also hydrolyzed in acid and the product rechromatographed alone (3) and together with authentic adenine (4). The large peak eluting at the void of the column is caused by the high salt content of the samples and was also obtained in buffer controls. 
accurately quantitated. Excretion, as determined only by the difference in the area of the peak containing $\mathrm{N}^{6}, 2^{\prime}$-O-dimethyladenosine before and after incubation with ADA, ranged from $<0.5-2.9 \mathrm{nmoles} / \mathrm{mg}$ creatinine with apparent overlap between ADA deficient and nonADA deficient children (data not shown).

Analysis by HPLC of anion exchange fractions 1,3 and 4 and unfractionated urine. We sought to determine if there were ADA sensitive compounds in the three remaining fractions separated by chromatography of urine on the anion exchange column. We found 1-methyladenosine in fraction 1, where the authentic 1methyladenosine is also found (Fig. 1) and this amount was included in the quantitation of total excretion (page 5, Table 2). No other ADA sensitive compounds were detected in any other fraction, but any alkali unstable compounds would not be detected. We also could not detect any additional ADA sensitive compounds in whole urine not pretreated by anion exchange chromatography. The multiple compounds present in whole urine could have obscured additional ADA sensitive compounds.

Effect of erythrocyte exchange transfusion on excretion of adenine nucleosides. All four children were treated by partial erythrocyte exchange transfusions (patients 1-3) or a combination of total and partial exchange transfusions (patient 4) (41). The normal erythrocytes contain both the deficient enzyme and transport sites for nucleosides. We sought to determine if such transfusions affected excretion of 2'-O-methyladenosine and $\mathrm{R}$-adenosine in the same manner that such transfusions have been reported to diminish excretion of $2^{\prime}$-deoxyadenosine and to a lesser extent, adenosine (36). We arbitrarily chose urines obtained 1 month, 3 months and 2 years after the start of repeated transfusions. As has been previously reported, 2 '-deoxyadenosine excretion fell dramatically after the first transfusion and was maintained at these lowered concentrations; however, they are still markedly elevated compared to normal. Adenosine excretion also diminished, although it was much less dramatic and remained higher than in normals. Excretion of $\mathrm{R}$-adenosine fell rapidly in all four patients and was

Table 4. Effect of erythrocyte exchange transfusions $(T x)$ on excretion of adenine nucleosides ${ }^{1}$ by $A D A$ deficient patients ${ }^{1}$

\begin{tabular}{|c|c|c|c|c|c|}
\hline \multirow[b]{2}{*}{ Adenine nucleoside } & \multicolumn{4}{|c|}{ Patients } & \multirow[b]{2}{*}{ Normal } \\
\hline & 1 & 2 & 3 & $4^{2}$ & \\
\hline \multicolumn{6}{|l|}{ 2'-deoxyadenosine } \\
\hline Pre $T x$ & 221.0 & $414.0^{3}$ & 1090.0 & 572.0 & \\
\hline Post Tx $1 \mathrm{mo}$ & 54.5 & 89.6 & 40.0 & $3.7^{1 \mathrm{a}}$ & \\
\hline Post Tx $3 \mathrm{mo}$ & 37.0 & 49.2 & 21.5 & $3.2^{\mathrm{b}}$ & \\
\hline Post Tx $24 \mathrm{mo}$ & 21.2 & 20.0 & 37.9 & & $<0.1$ \\
\hline \multicolumn{6}{|l|}{ Adenosine } \\
\hline Pre Tx & 37.1 & $23.5^{3}$ & 29.8 & 27.3 & \\
\hline Post Tx $1 \mathrm{mo}$ & 15.2 & 16.7 & 22.8 & $10.6^{1 \mathrm{a}}$ & \\
\hline Post Tx $3 \mathrm{mo}$ & 19.5 & 14.8 & $15.0^{1 \mathrm{a}}$ & $4.6^{1 \mathrm{~b}}$ & \\
\hline Post Tx $24 \mathrm{mo}$ & 12.1 & 9.4 & 22.9 & & $4.1 \pm 1.0$ \\
\hline \multicolumn{6}{|l|}{ 2'-O-methyladenosine } \\
\hline Pre Tx & 2.1 & $3.5^{3}$ & 2.2 & 0.7 & \\
\hline Post Tx $1 \mathrm{mo}$ & 2.0 & 2.3 & 0.6 & $0.1^{1 \mathrm{a}}$ & \\
\hline Post Tx $3 \mathrm{mo}$ & 3.3 & 2.4 & 0.4 & $0.2^{1 \mathrm{~b}}$ & \\
\hline Post Tx $24 \mathrm{mo}$ & 1.0 & 0.9 & 0.2 & & $<0.1$ \\
\hline \multicolumn{6}{|l|}{$\mathrm{R}$-adenosine } \\
\hline Pre Tx & 5.2 & $5.3^{3}$ & 6.9 & 4.6 & \\
\hline Post Tx $1 \mathrm{mo}$ & 2.1 & 2.4 & 1.9 & $1.0^{1 \mathrm{a}}$ & \\
\hline Post $\mathrm{Tx} 3 \mathrm{mo}$ & 4.0 & 1.7 & 1.7 & $1.2^{\mathrm{lb}}$ & \\
\hline Post Tx $24 \mathrm{mo}$ & 1.7 & 1.8 & 1.5 & & $1.4 \pm 0.4$ \\
\hline
\end{tabular}

' $\mathrm{nmoles} / \mathrm{mg}$ creatinine. Values are for urines obtained 13 days following transfusions except where indicated. "One day post transfusion. 'Seven days post transfusion. Patients $1-4$ are the same as in Table 2. Patients 1-3 were partially exchange transfused $(10-15 \mathrm{ml} / \mathrm{kg})$ every 2-3 wk for the first year and approximately every $5 \mathrm{wk}$ during the second year.

${ }^{2}$ Patient 4 was totally exchange transfused as well as partially transfused

${ }^{3}$ Seventy days following last transfusion. reduced from 4-5-fold increase to essentially normal concentrations. Excretion of 2'-O-methyladenosine decreased following transfusions, initially at a slower rate but remained detectable (Table 4).

Increasing age would not appear to be the reason for the observed diminution of excretion over the 2 year period since ADA deficient patient 2 was as old ( $2 \frac{1 / 2}{2}$ years of age) before treatment as were patients $I$ and 3 at the end of the study ( 2 and $2 \frac{1}{2}$ years of age). Disease state would also not appear to be the determining factor for alterations in excretion, because ADA deficient patient 1 was clinically healthy while patient 3 remained critically ill throughout the first 3 months of the study (27). The controls similarly represented a spectrum of severely ill to clinically healthy children.

Excretion of $N^{2}$-methylguanosine. We also determined the excretion of a nonadenine containing modified purine nucleoside, $\mathrm{N}^{2}$-methylguanosine. There was no apparent difference in the excretion of this nonadenine containing modified nucleoside by ADA and nonADA deficient children. Thus the ADA deficient children excreted between 15 and 30 nmoles/mg creatinine ( 19.8 $\pm 0.6, n=4$ ) compared to excretion by nonADA deficient children which ranged from $16-46(27.3 \pm 13.2, n=4)$.

\section{DISCUSSION}

We have found that ADA deficient patients, but not normals, excrete detectable quantities of the modified adenine nucleoside, 2 '-O-methyladenosine. We have also found two additional modified adenine nucleosides not previously reported in human urine. These nucleosides are $\mathrm{N}^{6}, 2^{\prime}-\mathrm{O}$-methyladenosine and an, as yet, incompletely characterized modified adenine nucleoside, $\mathbf{R}$-adenosine. ADA deficient patients excrete approximately 4-fold increased amounts of this unidentified, modified adenine nucleoside. Our inability to determine if $\mathbf{R}$-adenosine is modified on the purine or the ribose by the methods used suggests that either the sugar is modified on sites other than the $2^{\prime}, 3^{\prime}$ hydroxyls or that the modification of the purine ring is labile to the conditions of acid hydrolysis utilized. Because both normals and ADA deficient patients excreted $\mathrm{R}$-adenosine, we considered that indentification of the exact modifications of R-adenosine, although of general interest, was not likely to be of major significance for ADA deficiency. Studies are in progress to further characterize this compound. We have also confirmed previous reports of massively increased excretion of $2^{\prime}$-deoxyadenosine $(9,28,32,36,37,50)$ as well as moderately (approximately 6-fold) increased excretion of adenosine by ADA deficient patients (9). Excretion of 1 -methyladenosine also appeared to be slighty increased. We have not found any difference in excretion of a nonadenine contained modified nucleoside $\left(\mathrm{N}^{2}\right.$-methylguanosine), supporting the idea that observed differences in adenine nucleoside excretion do not reflect some nonspecific alteration in nucleoside metabolism. Consistent with the hypothesis that the increased excretion of all four adenine nucleosides results from deficiency of ADA, we have also found that the excretion of $\mathrm{R}$-adenosine and 2'-O-methyladenosine as well as of adenosine and $2^{\prime}$-deoxyadenosine by ADA deficient patients is diminished following "enzyme replacement therapy" with partial erythrocyte exchange transfusions $(36,41)$.

Modified adenine nucleosides, other than $2^{\prime}$-deoxyadenosine, are constituents of RNA in mammals and other eukaryotes (34, $39,47,51,53)$ and therefore their excretion should reflect turnover of RNA. Modification of the adenine nucleoside moiety appears to occur only post-transcriptionally, after incorporation into RNA. It does not appear to involve direct incorporation of modified adenine compounds into RNA. The extent and type of modification varies with the different classes of RNA. For example, $N^{6}, 2^{\prime}$ O-dimethyl compounds occur in the cap sturcture of mRNA and in low molecular weight nuclear RNA; 2'-O-methyladenosine occurs in ribosomal RNA as well as in the cap structure of mRNA and 1 -methyladenosine is a feature of $\operatorname{tRNA}(7,13,31,34,35,39$, $47,48,51,53)$. Whether modified adenine nucleosides in urine are derived from turnover of endogenous RNA, of dietary purines or 
of RNA of enteric bacteria cannot be definitely determined from the studies reported here but would require "tracer" studies. The source of increased adenine nucleosides excreted by ADA deficient patients is irrelevant in relation to the possible pathologic effects of accumulation of such compounds, although the source may have significance in relation to possible therapeutic modulation.

In normal patients, urinary excretion of modified adenine nucleosides will, in theory, depend on several factors including the relative abundance of each of the compounds in RNA, the turnover rates of the RNA in which they occur, the clearance by the kidneys of each compound, as well as the relative ability of ADA to remove the group attached at the $\mathrm{C} 6$ position of each of the compounds. $\mathrm{N}^{6}$-methyladenosine, l-methyladenosine, $\mathrm{N}^{6}, 2^{\prime}$-O-dimethyladenosine and $\mathrm{R}$-adenosine are poor substrates for calf; avian and/or human ADA $(1,8,18,43,56$ and unpublished observations). It is therefore not surprising that these latter four compounds are found unaltered in urine of ADA normal humans. The finding that ADA deficient children excrete increased amounts of $\mathrm{R}$-adenosine and possibly $\mathrm{l}$-methyladenosine, both relatively poor substrates for calf $\mathrm{ADA}$, suggests that deamination by adenosine deaminase may play some role in the metabolism even of compounds that are relatively poor substrates for the enzyme. Adenosine, 2'-deoxyadenosine and 2'-O-methyladenosine are excellent substrates for human ADA as they are for calf ADA (1, 8, 56 and unpublished observations). Consistent with their rapid deamination by human ADA, 2'-O-methyladenosine and 2 -deoxyadenosine have not been detected in normal human urine but are found in urines of ADA deficient children. Adenosine, an excellent substrate for ADA, is found in urine of normals, although in lower concentrations than in urine of ADA deficients. The presence of adenosine in normal urine may reflect the relative abundance of the adenine-ribose moiety, which is present not only in RNA but exists in high concentration as free adenine nucleotides and in additional compounds such as $\mathbf{S}$-adenosylmethionine. Alternatively, urinary adenosine may be primarily derived directly from the kidney.

The possible significance and role of these modified adenine nucleosides in the pathophysiology of ADA deficiency is, at the moment, speculative. The concentrations of 2 '-O-methyladenosine and $\mathbf{R}$-adenosine we have measured in urine are insignificant compared to the massive concentrations of deoxyadenosine; however, concentrations in urine may not reflect concentrations of compounds in plasma or of the compounds and/or their metabolites in cells. Indeed, the relative concentration of deoxyadenosine and adenosine in plasma are essentially equal and do not reflect the massive accumulation of dATP in cells nor of deoxyadenosine in urine. Therefore, further investigation of concentrations of the compounds described here and/or their metabolites in plasma and cells would seem warranted.

There are several possible sites at which these compounds or their phosphorylated derivatives could interfere with normal cellular metabolism. These include binding of mRNA to ribosomes, inhibition of $S$ adenosyl homocystine hydrolase and thus $S$ adenosyl methionine dependent methylation or alteration of cyclic AMP concentrations via "purinergic" cell receptors $(11,29,30$, 47). We have examined the effect of several of these compounds on the ability of lymphocytes rendered artificially ADA deficient to respond to phytohemagglutinin, a response which primarily reflects function of fully differentiated $T$ cells. We have found that 2 '-O-methyladenosine is as potent in vitro as adenosine in inhibiting lymphocyte response to mitogens but markedly less potent than deoxyadenosine. It remains to be determined if methylated adenine nucleosides have significant effects on in vitro models of differentiation of immune function and particularly of B cell function. Since methylated adenine nucleosides would not be expected to accumulate in purine nucleoside phosphorylase deficiency such differences might explain the profound impairment of $B$ cell function observed in ADA deficiency and not in purine nucleoside phosphorylase deficiency.

\section{REFERENCES AND NOTES}

I. Agarwal, R. P., Sagar, S. M. and Parks, R. E. Jr.: Adenosine deaminase from human erythrocytes. Biochem. Pharmacol., 24: 693 (1975)

2. Carson, D. A., Kaye, J., and Seegmiller, J. E.: Lymphospecific toxicity in adenosine deaminase deficiency and purine nucleoside phosphorylase deficiency: possible role of nucleoside kinases. Proc. Natl. Acad. Sci., 74: 5677 (1977).

3. Chen, S.-H., Ochs, M. D., Scott, C. R., Giblett, E. R., and Tingle, A. J.: Adenosine deaminase deficiency. Disappearance of adenine deoxynucleotides from a patient's erythrocytes after successful marrow transplantation. J. Clin. Invest., 62: 1386 (1978).

4. Chheda, B. G.: Purine, pyrimidine, pyridine, and imidazole derivates excreted in human urine. In: G. D. Fasman, Ed.: Handbook of Biochemistry and Molecular Biology. Vol. 1, 3rd Edition. pp. 251-270 (CRC Press, Cleveland, OH, 1975).

5. Cohen, A. R., Hirschhorn, R., Horowitz, S. D., Rubinstein, A., Polmar, S. H., Hong, R., and Martin, D. W. Jr.: Deoxyadenosine triphosphate as a potentially toxic metabolite in adenosine deaminase deficiency. Proc. Natl. Acad. Sci., 75: 472 (1978).

6. Coleman, M. S., Donofrio, J., Hutton, J. J., Hahn, L., Daoud, A., Lampkin, B., and Dyminski, J.: Identification and quantitation of adenine deoxynucleotides in erythrocytes of a patient with adenosine deaminase deficiency and severe combined immunodeficiency. J. Biol. Chem., 253: 1619 (1978).

7. Crain, P. F., Choi, Y. C., Busch, H., and McCloskey, J. A.: Characterization of $\mathrm{N}^{6}, 2^{\prime}$-O-dimethyladenosine from nuclear RNA of Novikoff Hepatoma. Nucl. Acids. Res., S: 771 (1978).

8. Daddona, P. E. and Kelley, W. N.: Human adenosine deaminase-purification and subunit structure. J. Biol. Chem., 252: 110 (1977).

9. Donofrio, J., Coleman, M. S., Hutton, J. J., Daoud, A., Lampkin, B., and Dyminski, J.: Overproduction of adenine deoxynucleosides and deoxynucleotides in adenosine deaminase deficiency with severe combined immunodeficiency disease. J. Clin. Invest., 62: 884 (1978).

10. Hirschhorn, R.: Clinical delineation of adenosine deaminase deficiency. In: Enzyme Defects and Immune Dysfunction (Ciba Foundation Series 68). pp. 35-54 (Excepta Medical, Amsterdam, 1979).

11. Fain, J. N. and Malbon, C. C.: Regulation of adenylate cyclase by adenosine. Molec. Cell Biochem., 25: 143 (1979).

12. Fox, I. H., Kaminska, J., Wortmann, R. L., and Halsey, D. L.: Deoxyadenosine inhibits DNA synthesis in cultured human fibroblasts. J. Lab. Clin. Med., 94: 52 (1979).

13. Gauss, D. H., Gruter, F., and Sprinzl, M.: Compilation of tRNA sequences. In: P. R. Schimmel, D. Soll, J. N. Abelson, Ed.: Transfer RNA: Structure, Properties and Recognition. pp. 520-535 (Cold Spring Harbor, New York, NY, 1979).

14. Gelfand, E. Personal communication.

15. Giblett, E. R., Anderson, J. E., Cohen, F., Pollara, B., and Meuwissen, H. J.: Adenosine deaminase deficiency in two patients with severely impaired cellular immunity. Lancet, $11: 1067$ (1972).

16. Green, H. and Chan, T.-S.: Pyrimidine starvation induced by adenosine in fibroblasts and lymphoid cells: role of adenosine deaminase. Science, 182: 836 (1973).

17. Hall, R. H.: Modified nucleosides: physical properties, chemical synthesis and natural occurrence. In: The Modified Nucleosides in Nucleic Acids. pp. $17-$ 185 (Columbia University, Press, New York, NY, 1971)

18. Hall, R. H., Alam, N. S., McLennan, B. D., Terrine, C., and Guern, J.: $N^{6}-\left(\Delta^{2}-\right.$ isopentenyl) adenosine: its conversion to inosine, catalyzed by adneosine amino hydrolases from chicken bone marrow and calf intestinal mucosa. Can. J. Biochem., 49: 623 (1971).

19. Dunn, D. B., and Hall, R. H.: Natural occurrence of the modified nucleosides. In: G. D. Fasman: Handbook of Biochemistry and Molecular Biology. Vol. 1, 3rd Edition. pp. 65-215 (CRC Press, Cleveland, OH, 1975).

20. Hartwick, R., Jeffries, A., Krstulovic, A., and Brown, P. R.: An optimized assay for adenosine using reverse phase high pressure liquid chromatography. J. Chromat. Sci., 16: 427 (1978).

21. Hershfield, M. S., Kredich, N. M., Ownby, D. R., Ownby, D. R., Ownby, H., and Buckley, R.: In vivo inactivation of erythrocyte S-adenosyl homocysteine hydrolase in adenosine deaminase-deficiency patients. J. Clin. Invest., 63: 807 (1979).

22. Hirschhorn, R.: Defects of purine metabolism in immunodeficiency diseases. In: R. S. Schwartz, Ed.: Progress in Clinical Immunology. Vol. III, pp. 67-83 (Grune \& Stratton, New York. NY, 1977).

23. Hirschhorn, R., Bajaj, S., Borowsky, W., Kowalski, A., Hong, R., Rubinstein, A., and Papageorgiou, P.: Differential inhibition of adenosine deaminase deficient peripheral blood lymphocytes and lymphoid line cells by deoxyadenosine and adenosine. Cell Immunol., 42: 418 (1979).

24. Hirschhorn, R., Grossman, J., and Weissman, G.: Effect of cyclic 3',5'-adenosine monophosphate and theophylline on lymphocyte transformation. Proc. Soc. Exp. Biol. Med., 133: 1361 (1970).

25. Hirschhorn, R. and Martin, D. W. Jr.: Enzyme defects in immunodeficiency diseases. In: P. Miescher, H. Muller-Eberhard, Ed.: Springer Seminars in Immunopathology. pp. 299-321 (Springer-Verlag, Heidelberg, 1978).

26. Hirschhorn, R., Papageorgiou, P. S., Kesarwala, H. H., and Taft, L. T.: Amelioration of neurologic abnormalities after "enzyme replacement" in adenosine deaminase eficiency. N. Engl. J. Med., 303: 377 (1980).

27. Hirschhorn, R., Papageorgiou, P., Rubinstein, A., and Rosen, F. S.: Transfusion vs bone marrow transplantation in combined immunodeficiency. Clin. Res., 
27: 507 A (1979).

28. Hirschhorn, R., Roegner, V., Rubinstein, A., and Papageorgiou, P.: Plasma deoxyadenosine, adenosine, and erythrocyte deoxy-ATP are elevated at birth in an adenosine deaminase-deficient child. J. Clin. Invest., 65: 768 (1980).

29. Hoffman, J. L.: Biosynthesis of S-N $\mathrm{N}^{\mathbf{6}}$ methyl adenosine homocysteine. J. Biol. Chem., 253: 2905 (1978)

30. Hirschhorn, R.: Incidence and prenatal detection of adenosine deaminase deficient and purine nucleoside phosphorylase deficiency. In: B. Pollara, R. J. Pickering, H. G. Meuwissen, I. Porter, Eds.: Inborn Errors of Specific Immunity. Pp. S-15 (Academic Press, New York, NY, 1979).

31. Kaehler, M., Coward, J., and Rottman, F.: In vivo inhibition of Novikoff cytoplasmic messenger RNA methylation by S-tubercidinyl homocysteine. Biochem., 16: 5770 (1977).

32. Kuttesch, J. F., Schmalstieg, F. C., and Nelson, J. A.: Analysis of adenosine and other adenine compounds in patients with immunodeficiency diseases. J. Liq. Chromat., J: 97 (1978).

33. Lowry, O. H., Rosebrough, N. J., Farr, A. L., and Randall, R. J.: Protein measurement with the Folin phenol reagent. J. Biol. Chem., 193: 265 (1951)

34. Maden, B. E. H.: Eukaryotic ribosomal RNA methylation: summary and recent developments. In: E. Usdin, R. T. Borchardt, C. R. Creveling, Eds: Transmethylation. pp. 38I-398 (Elsevier/North Holland, New York, NY, 1978)

35. Maden, B. E. $H$. and Salim, M.: The methylated nucleotide sequences in HeLa cell ribosomal RNA and its precursors. J. Mol. Biol., 88: 133 (1974).

36. Mills, G. C., Goldblum, R. M., Newkirk, K. E., and Schmalstieg, F. C.: Urinary excretion of purines, purine nucleosides, and pseudouridine in adenosine deaminase deficiency. Bichem. Med., 20: 180 (1978).

37. Mills, G. C., Schmalstieg, F. C., Trimmer, K. B., Goldman, A. S., and Goldblum, R. M.: Purine metabolism in adenosine deaminase deficiency. Proc. Natl Acad. Sci., 73: 2867 (1976).

38. Mitchell, B. S., Mejias, E., Daddona, P. E., and Kelley, W. N.: Purinogenic immunodeficiency diseases: selective toxicity of deoxyribonucleosides for $T$ cells. Proc. Natl. Acad. Sci., 75: 5011 (1978).

39. Nishimura, S.: Minor components in transfer RNA. In: J. N. Davidson, W. E Cohen, Eds.: Progress in Nucleic Acid Research and Molecular Biology. Vol. 12, pp. 49-85 (Academic Press, New York, NY, 1972).

40. Planet, G. and Fox, I. H.: Inhibition of phosphoribosyl pyrophosphate synthesis by purine nucleosides in human erythrocytes. J. Biol Chem., 251: 5839 (1976).

41. Polmar, S. H., Stern, R. C., Schwartz, A. L., Wetzler, E. M., Chase, P. A., and Hirschhorn, R.: Enzyme replacement therapy for adenosine deaminase deficiency and severe combined immunodeficiency. New Engl. J. Med., 295: 1337 (1976).

42. Ratech, H. and Hirschhorn, R.: Identification of adenosine and eight modified adenine nucleosides using reversed-phase high pressure liquid chromatography and enzymatic peak shift with adenosine deaminase. J. Chromat. Biomed. Applicat., 183: 499 (1980).

43. Ratech, H., Thorbecke, G. J., Meredith, G., and Hirschhorn, R.: Comparison and possible homology of isozymes of adenosine deaminase in aves and humans. Enzyme, 26: 74 (1981)

44. Rubinstein, A., Hirschhorn, R., Sicklick, M., and Murphy, R. A.: In vivo and in vitro effects of thymosin and adenosine deaminase on adenosine-deaminasedeficient lymphocytes. New Engl. J. Med., 300: 387 (1979)

45. Schlenk, F., Zydek-Cwick, C. R., and Hutson, N.: Enzymatic deamination of adenosine sulfur compounds. Arch. Biochem. Biophys., 42: 144 (1971).

46. Schmalstieg, F. C. Nelson, J. A. Mills, G. C. Monahan, T. M., Goldman, A. S and Goldblum, R. M.: Increased purine nucleotides in adenosine deaminasedeficient lymphocytes. J. Pediatr., 91 : 48 (1977).

47. Shatkin, A. J.: Capping of eucaryotic mRNA's. Cell, 9: 645 (1976).

48. Shibata, H., Ro-Choi, T. S., Reddy, R., Choi, Y. C., Henning, D., and Busch, H. The primary nucleoside sequence of nuclear $U 2$ ribonucleic acid. $J$. Biol. Chem., 250: 3909 (1975).

49. Simmonds, H. A., Panayi, G. S., and Corrigal, V.: The role of purine metabolism in immunodeficiency: adenosine deaminase activity and deoxyadenosine catabolism. Lancet, $I$ : 60 (1978).

50. Simmonds, H. A., Sahota, A., Potter, C. F., and Cameron, J. S.: Purine metabolism and immunodeficiency: urinary purine excretion as a diagnostic screening test in adenosine deaminase and purine nucleoside phosphorylase deficiency. Clin. Sci. Molec. Med., 54: 579 (1978).

51. Soll, D.: Enzymatic modifications of transfer RNA. Science, 173: 293 (1971).

52. Uberti, J., Lightbody, J.. and Johnson, R.: The effect of nucleosides and deoxycoformycin on adenosine and deoxyadenosine inhibition of human lymphocyte activation. J. Immunol., 123: 189 (1979).

53. Weinberg, R. A. and Penman, S.: Small molecular weight amono disperse nuclear RNA. J. Mol. Biol., 38: 298 (1968).

54. Wilson, J. M., Mitchell, B. S., Daddona, P. E., and Kelley, W. N.: Purinogenic immunodeficiency disease: differential effects of deoxyadenosine and deoxyguanosine on DNA synthesis in human T lymphoblasts. J. Clin. Invest., 64 : 1475 (1979).

55. Wolberg, G., Zimmerman, T. P., Hemstra, K., Winston, M. and Chu, L.-C. Adenosine inhibition of lymphocyte-mediated cytolysis: possible role of cyclic adenosine monophosphate. Science, 187: 957 (1975).

56. Zielke, C. L. and Suelter, C. H.: Purine, purine nucleoside and purine nucleotide amino hydrolases. In: P. D. Boyer, Ed.: The Enzymes, Vol. 4, Third Ed. pp. 54-64 (Academic Press, New York, NY, 1971).

57. The authors thank Dr. J. Wilner for help in obtaining urines.

58. Requests for reprints should be addressed to: Dr. Rochelle Hirschhorn, Department of Medicine and Pathology, New York University School of Medicine. 550 First Avenue, New York, NY 10016

59. This research was supported by NIH AI 10343 and National Foundation \#6-4 Howard Ratech was supported by National Cancer Institute Training Grant \#5 T32 CA 09161 .

60. Received for publication May 13, 1981.

61. Accepted for publication October 2, 1981. 